Ethiopian Journal of Environmental Studies \& Management 10(1): 22 - 37, 2017.

ISSN: 1998-0507

doi: http://dx.doi.org/10.4314/ejesm.v10i1.3

Submitted: September 26, 2016

Accepted: January 19, 2017

\title{
PROPERTY-USE CONVERSION IN LAGOS METROPOLIS IN THE CONTEXT OF THE VACILLATING REGULATORY APPROACHES OF THE PHYSICAL DEVELOPMENT AGENCY
}

\author{
*BABATOLA, 0.1 AND ONI, A.F. ${ }^{2}$ \\ ${ }^{1}$ Department of Geography, University of Lagos \\ ${ }^{2}$ Department of Urban and Regional Planning, Yaba College of Technology, Yaba, Lagos
}

\begin{abstract}
The lopsided focus of research on metropolitan housing deficit, which preponderantly neglects the import of use-conversion of properties in the assessment of the problem, motivated this paper. Primarily, it analyzes the inter-use dynamics of the housing-stock in metropolitan Lagos, Nigeria, employing the field-survey method to draw out random samples of buildings from streets that were compiled through stratified-cum-random sampling processes. Its objectives are two-fold. First, it examines the pattern of inter-use conversion of buildings among Lagos' criterially-delineated metropolitan regions. Two, it examines the extent to which altering the criterion used in sub-regionalizing Lagos into different genres of metropolises can change the capability of the model which attempts to predict useconversion for the metropolis; including exploring the relevance of the obtained results for enhancing physical development regulatory strategy in the metropolis. Its findings among others show that the current usage of buildings differs in varying degrees among the delineated metropolitan regions, while inter-use conversion pattern generally under-favours residential-housing usage. A logit-model analysis of the capabilities of the two alternative metropolitan expressions of Lagos to show clarifiable differences in the pattern of useconversion among their respective individual sub-regions, throws up the importance of applying strategies that are enriched with spatial thinking in actualizing housing-related policy and planning regulations in the metropolis. Conclusively, the paper stressed the need for researchers to task their innovative capabilities in devising appropriate criteria for generating spatial configurations, which are contextually-relevant to individual metropolises, as they tackle use-conversion of the housing stock and related issues in such cities.
\end{abstract}

Key Words: Lagos metropolis, Building-use-conversion, Residential stock, logit model

Introduction

Inadequate housing is a common challenge in many cities of the development-lagging world, including Lagos, Nigeria's foremost metropolis
(Akinmoladun and Oluwoye, 2007). Researchers have focused on this multisided problem from different explanatorycum-analytical perspectives. While Aluko (2011) and some others focus on how

*Corresponding Author: Babatola, O.

Email: obabatola@unilag.edu.ng 
immigration promotes housing deficit, Ukway et al. (2012) pinpoint the defective mortgage system. Others, including Hardoy and Satterthwaite (1981); Magigi and Majani (2006) and Enisan and Ogundiran (2013) highlight differential access to urban land for house-building purpose.

To date what obtains is a preponderant pattern of interest in housing deficit, which over-concentrates on the supply-related issues, culminating in the exclusion of other equally-relevant themes. Strikingly understudied for example, is how the nature of a government's official regulation of housing development and redevelopment in a given metropolis can impact on the degree to which different categories of property usage suffer reduction in their relative availability over time in the housing market. Such an analysis, which lies thematically outside the housing-supply issues, is very germane, as it addresses how the government in performing its assigned housing responsibilities, may impact either negatively or positively on different housing uses, particularly the residential housing.

Incidentally, regardless of the perspective employed in the analysis of the housing deficit, the commanding role of the government has a two-fold relevance. Specifically, the government is expected to have an input in the total housing provision effort and also employ appropriate policy and legal instruments to regulate building composition in a way that commercialism does not inequitably undermine the availability of residential housing. The achievement of the government in this regard would determine how far it is succeeding on a major welfare objective of improved access to residential housing which has been a major focus of the UNHabitat.

Existing housing deficit researches in Lagos exhibit skewedness towards the supply theme, paying little attention to how regulatory issues, such as the property development edict revision by the Lagos State Physical Development Agency (LASPPDA) in 2007, could have impinged on specific property-use deficit in the metropolis. That revision by LASPPDA by allowing the payment of 'heavy financial' penalty, including the possibility of granting such properties subsequent approval, instead of the initial outright demolition of property, suggests that increasing contraventions were either manifesting or threatening in the metropolis.

Indeed prior to that revision, LASPPDA's capability at effectively monitoring and enforcing the physical development prescription of the metropolis' zoning ordinance had plummeted, and had been ascribed to the increasing sprawling magnitude of the metropolis and alleged official corruption (Aluko, 2011).Regardless of the foregoing development, researchers to date do not show appreciable interest in the analysis of property-use conversion, despite the implication of such conversion on the availability of specific-uses of housing in Lagos.

The foregoing background informs the focus of this paper which examines property-use conversion in Lagos metropolis. However, in addition to ascertaining use-conversion pattern, this paper examines also the factors which underpin use-conversion given their relevance in designing models of useconversion of properties. Such models are valuable in that they have potentials to 
reveal important variables that may be employed by the metropolitan regulatory agency to devise more effective physical development monitoring strategy that would facilitate the achievement of the original objective of the agency, without recourse to the inequitable financial penalty option. This paper in essence focuses on three primary objectives to achieve its goal.(i) It examines and compares specified attributes of the metropolitan buildings which may impinge on the likelihood of use-conversion decision; (ii) It analyzes the pattern and magnitude of use-conversion of houses in the metropolis and; (iii)It develops and compares models of building-use conversion, using two different spatial conceptions of Lagos metropolis to demonstrate that altering the spatial conception of a metropolis may make the difference in the degree of success achieved in the assigned responsibilities of a metropolitan development regulatory agency.

\section{Literature Review and Analytical Framework}

Supply-related issues have dominated the focus of research on the state of housing provision in cities of the developing regions of the world, paying little attention to the role of property-use conversion. To start with, the two terms, property-use conversion and building-use conversion are synonymously used in this paper. Mabogunje's (2007) estimate of 23 housing stock per 1000 inhabitants is a typical analysis which portrays serious housing deficit, without any clue about the incidence of property-use conversion reflected by that statistic.

Nubi (2008) addressed deficit in the aggregate housing needs rather than in the residential stock, thus having a limited purview which excluded property-use conversion.

Oshodi (2010), whose research interest appreciably coincides with those of Ademiluyi and Raji (2008) and Ukwayi et al. (2012) examined primarily the role of the Federal Mortgage Bank in housing deficit scenario. The study which highlights how diminishing budgetary allocation, increasing price of construction materials as well as the disadvantaged location of the Bank vis-à-vis its countrywide area of patronage undermined her envisaged housing-intervention relevance, overlooks the probable role of property-use conversion.

Akinmoladun and Oluwoye (2007) highlighted the gross imbalance between housing supply and its escalating demand. They emphasized the importance of involving the significant stakeholders in addressing the issue of housing deficit; a task which requires the facilitatory role of the government.

Alufohai (2013) reviewed the various programmatic strategies employed to date to improve on the physical development and housing provision in the metropolis, commencing from the first-ever effort of the Lagos Executive Development Board (LEDB) in the 1950s to the current operations of the Lagos State development and Property Corporation (LSDPC). Among others, his findings underscores the need to effectively ensure that building uses conform to the officially-granted approval so as to avert overcommercialization of property market which is often detrimental to some competitively-vulnerable uses like the residential purpose.

Opoko and Oluwatayo (2014) examining the gross insufficiency of the housing stock, highlights how the rent 
edict enacted to protect the low-income tenants was breeding the phenomenon of gentrification contrary to its original intention. The reality of unintended effects of many policies recommends that governments must incorporate anticipatory safeguards against unintended developments which may frustrate policies' genuine intentions.

Djibril et al. (2012) study of Abdijan on the other hand shows how the overlapping functional responsibilities of complementary metropolitan development agencies negatively obstructed the process of housing provision for those making effective demands. It shows how regulatory legal controls can constitute impedance to a process designed to achieve seamless housing provision.

Most researchers on housing shortage in South Africa including Mistro and Hensher (2009); Franklin (2011); Bolnick et al. (2011); Housing Development Agency (HDA) (2012); Massey (2013) and South Africa.info (2016) see the housing deficit in South African cities and the mushrooming of sub-standard shanties as relics of the inequitable apartheid system. Ziblim (2013) notes that intervention strategies which aimed at rebuilding existing shanties with governmentmobilized funds complemented by voluntary technical-cum-labour services by the target beneficiaries failed expectations, grossly undermining intervention outcomes. He, however, observed that regional differences in the spatial organization of the intervention-targeted settlements influenced the degree of intervention success.

Specifically, wherever shanties that are endowed with the voluntarily-yielded intervention-relevant resources occur in close proximity, the degree of intervention success achieved generally exceeds what obtains in regions in which they occur in disparate form and lack contiguity. The proven relevance of the spatial organizational attribute in this South African intervention suggests that the decision to consider the physical arrangement of any spatial phenomenon in addressing the challenges which confront the realization of its specified objectives may be very rewarding. Indeed, such a notion has been muted by notable geographers who articulate the niche of space or spatial organization in the development process (Mabogunje, 1980).

This study's main intention is to assess changes in the magnitude of useconversion of properties; first in the context of its implication on losses and gains by the competing uses and second, in the context of the government's revision of the edict under the guise that the monitoring strategy had become overburdening for the agency. Differing from that position, this paper posits that a change in the spatial monitoring strategy by the LSPPDA may well have assisted in achieving the needed compliance without an edict review in a direction that threatens the realization of its very fundamental intentions.

Specifically, it posits that the diminished regulatory capacity suffered by the LSPPDA in view of the increasing rate of metropolitan sprawl, being essentially a spatial organization problem, requires a strategy which incorporates spatial organization logic in addressing it. In other words, to what extent is a more effective monitoring and enforcement procedure achievable by employing strategies which regionalize the metropolis into contrasting sets of sub-areas, using different criteria in turns? The implication is that the particular 
spatial design which minimizes the tendency to dissipate energy and other related resources in the conduct of the monitoring and enforcement becomes the preferred strategy.

It is against this background that this study modeled factors of property-use conversion as its adjunct objective, comparing two different spatialorganization conceptions of the metropolis, in terms of whether or not they exhibit harmony or contrast in their patterns of use-conversion of buildings and their explanatory variables. The intention is not just to examine the extent to which the two models diverge or converge. It is also to examine the extent to which differences in the models could form a basis for showing how space-related approach for tackling the challenge confronting the LASPPDA may be a more equitable option, than the recourse to financial penalty, which has a greater risk of compromising the organization's primary objective.

\section{Methodology}

\section{Data Collection Procedure}

The non-availability of the secondarilyaccessible relevant data influenced the choice of the primary data acquisition method using the multi-stage stratified sampling technique. It focuses primarily on the metropolitan sub-division of Lagos state as defined in the Lagos Metropolis Regional Planning Division document (Lagos State Government, 1985). These comprise 13 Local Government Areas
(LGAs) classified by their historicodevelopment antecedents into five distinct planning-cum-development regions, namely, the traditional, the Colonial, the Post-Colonial, the Administrative and the Sub-urban (Fringe) regions. The size of the metropolis and the cost implications of a metropolitan-wide fieldwork informed the selection of five representative LGAs, namely Somolu (Traditional), Mainland (Colonial), Suru-Lere (Post-Colonial), Ikeja (Administration) and Ijaye/Ifako (Suburb/Fringe) as the focused study areas.

To fulfill the objective which examines whether a change of the criterion for spatial regionalization of the metropolis would differentiate the predictive capability of its building-use conversion model, another arrangement format of the metropolis is devised, which partitioned it into the 'high' and 'low' commercial regions respectively, as illustrated by Figure 1. Relying on the most reliable existing base-map (INEC, 2010), appropriate field-work maps of the selected LGAs were drawn for the sampling procedure which selected the streets as well as the buildings that formed the unit of analysis. The study categorizes the streets into two, namely the main and the minor streets, given the likelihood that the categorization would influence both accessibility and property rent. Using the probability proportionate to size (PPS) sampling techniques, six (6) and three (3) buildings were sampled respectively from the main and the minor streets. 


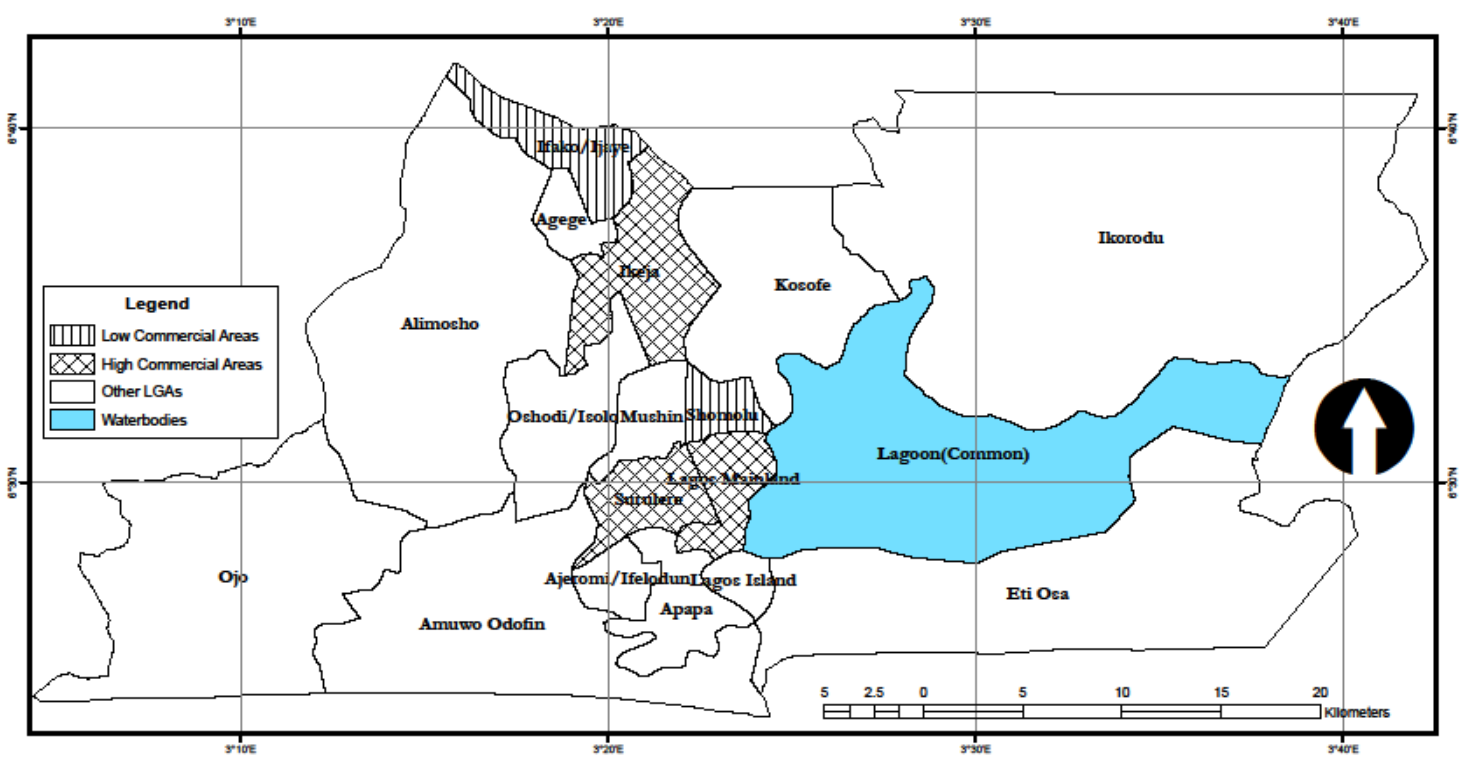

Figure 1: Lagos metropolis and the sub-regions of the study

\section{The Instrument}

Altogether, 729 copies of the questionnaire were given out, while 585 $(80.2 \%)$ were retrieved, in the following order: Somolu 135, (80.7\%); Mainland 136, (66.9\%); Surulere 135, (83.1\%); Ikeja $171,(95.3 \%)$ and Ifako/ijaye $139,(69.0 \%)$. The questionnaire elicited the following information about each building: its approval status at completion, its ownership, use-conversion and inheritance history as well as their physical characteristics and design attributes.

\section{Analytical Methods}

Analysis employed relevant packages in the Statistical Package for Social Sciences (SPSS). Frequency/percentile tables and matrices analysis in the form of the Markov chain transitional matrix were employed to capture building-use, buildings' dominant attributes and their inter-use conversion patterns. Also obtained parameters from the logistic regression analysis were employed to determine the model which 'fits' the occurrence of use-conversion better between the two devised conceptions of the metropolis.

\section{Results and Discussion}

This section analyses the data and discusses its results in line with the stated objectives. The six charts in Figure 2 illustrate how the selected attributes of buildings vary across the representative metropolitan regions. The variables comprise 'age of buildings'; 'the number of floors at completion'; 'the number of rooms at completion'; 'the residential weight', that is, the number of a building's rooms used solely as residence; the title held on the building and the "co-living status of landlord with tenants for each building'. Each chart illustrates the pattern of a specific variable for the five regions (LGA), while the last bar in each chart depicts the aggregate pattern of that variable for the entire metropolis.

'Buildings' age' shows the dominance of the 'pre-1991 buildings. It accounts for 
$87.8 \%$ of the metropolis-wide aggregate, and likewise constitutes the modal category for each of the 5 LGAs attaining its peak $(100 \%)$ in Shomolu. It is only in the Ifako/Ijaye that the combination of the 1991-2000 and 2001 to date exceed 30\% mark. Floor-level analysis shows that aggregately in the entire metropolis, the two-floor building design constitutes the modal class $(48.8 \%)$, followed by the 1 floor $(29.5 \%)$ and three-floor $(12.1 \%)$ category respectively. The percentage attained by the modal class in Ikeja, Surulere and Ifako exceeds the 50\% mark, while in the other two regions it was below $50 \%$.

Analyzing the 'number of rooms' shows that buildings with more than 10 rooms constitute the modal class, followed by the 7-10 and then the 1-6 room- categories. This pattern characterizes four of the five metropolitan regions; except Surulere where the percentage of the 1-6 room buildings exceeds those that have 710 rooms. 'Residential weight' as a variable seems to replicate to some extent the pattern which characterizes the 'number of rooms'. Generally, the proportions of buildings which devote few rooms exclusively for residential use are smaller than those which devote larger numbers for the same purpose. At the aggregate metropolitan level, $15.1 \%$ of buildings have between 1-6 rooms devoted exclusively to residential use, in contrast to $22.4 \%$ and $61.2 \%$ which exclusively devote 7-10 and more than 10 rooms respectively to residential purpose. Both Mainland and the Surulere exhibit some slight deviation from this pattern.

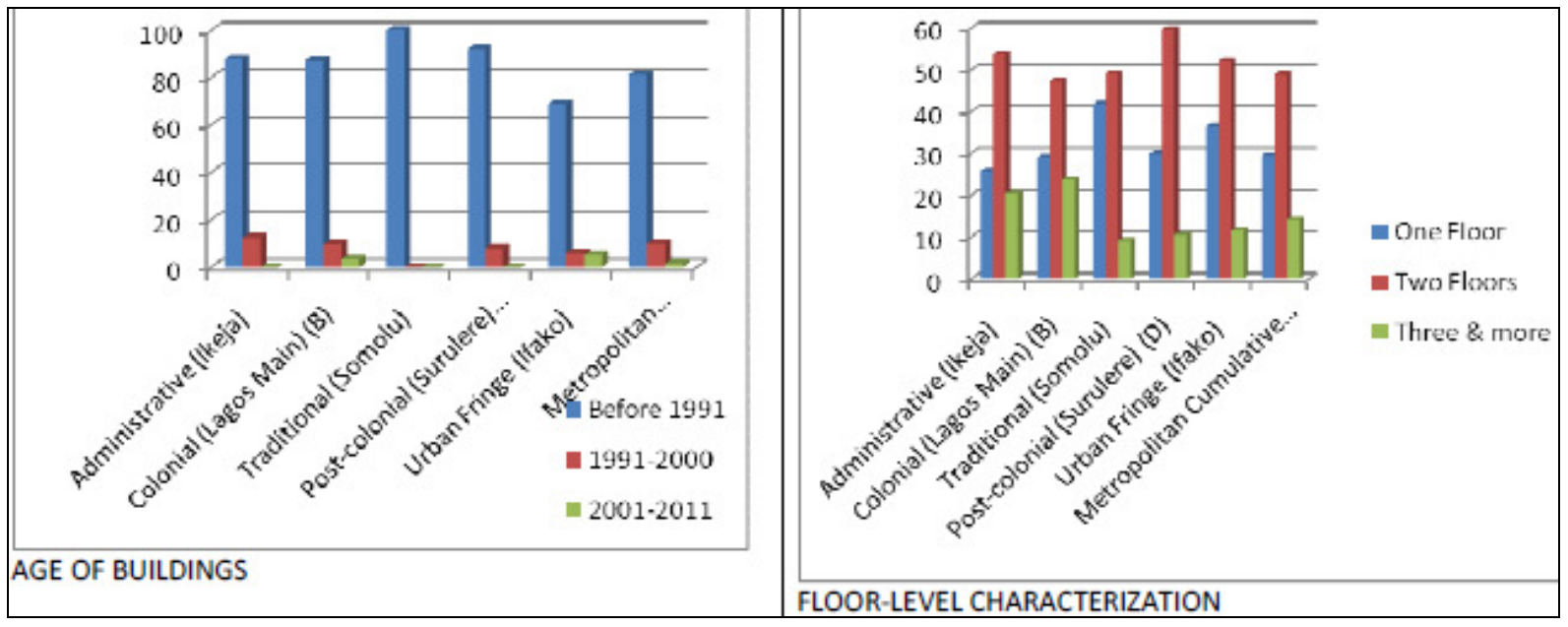




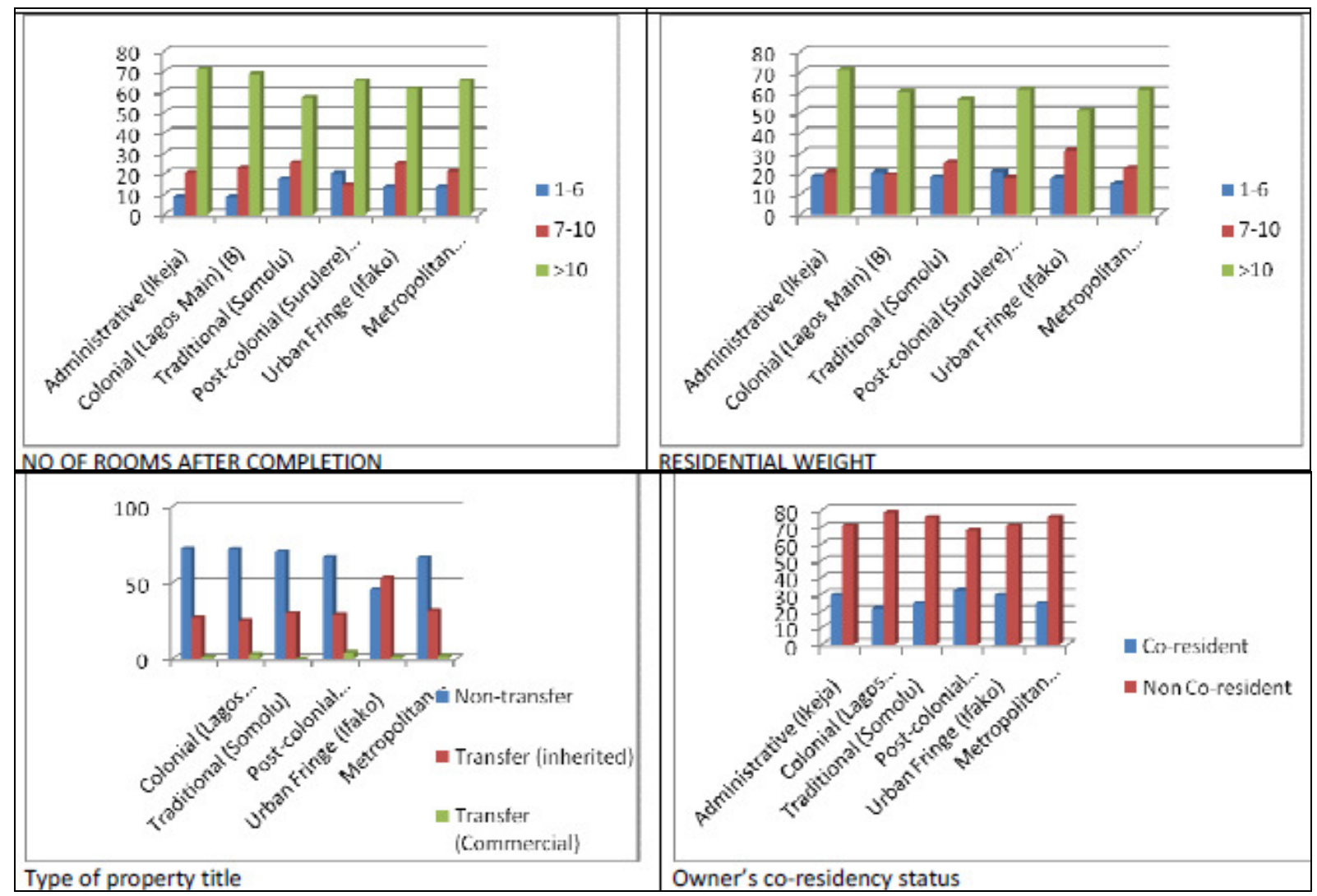

Fig 2: Current Attributes of sampled buildings across Lagos metropolitan regions

The pattern of titles on property shows that non-transferred right constitutes the single largest category $(66.3 \%)$ followed by the inherited transfer( $31.8 \%)$ and then the sale-transfer $(1.9 \%)$ right. There are slight variations at the regional level, the most distinct of which occurs in Somolu, where only 2 title categories are very prominent. The aggregate percentage of the buildings in which the owners reside, or co-reside with tenants amounts to $24.4 \%$ at the metropolitan level. This percentage is exceeded in Surulere (32.3\%) and Ifako/Ijaye $(29.2 \%)$ and slightly so in Somolu (24.5\%).
Use-specification patterns of Buildings at Completion across the metropolitan districts

Table 1 displays the pattern of building-use specification at the time of their completion, based on two spatial conceptions of Lagos metropolis employed in this paper.Use-specification when reckoned at the time of individual building's completion,shows that residential intention constituted the largest use-intention in both conceptions of the metropolis. Specifically, residential-use has $96.6 \%$, followed by $2.2 \%$ by the 'mixed-use'. Commercial and Religious uses individually has a little above $0.5 \%$, while Institutional use accounts for $0.17 \%$. The historical-administrative arrangement of the metropolis, with a larger number (5) 
of metropolitan sub-divisions, exhibits a greater degree of variations than the commercial-intensity categorization which has 2 categories. Under the first classification, residential-use attains its modal value in Somolu (99.1\%), followed by Surulere (97.6\%), Ikeja (96.3\%),
Mainland $(95.5 \%)$ and the lowest value of $93.8 \%$ in Ifako/Ijaye. Other building-uses registered low percentage values across the 5 regions. It varies between $0.8 \%$ and $5.2 \%$ for 'mixed uses' excluding Surulere. Religious-use interestingly registers $1 \%$ in Ifako/Ijaye region.

Table 1: Patterns of original use-intention of buildings at completion

\begin{tabular}{|c|c|c|c|c|c|c|}
\hline Metropolitan & Buildin & Jse Types & & & & Total \\
\hline Districts & Residential & Institutional & Commercial & Religious & Mixed & \\
\hline Colonial & 89 (95.5) & $1(1.1)$ & - & - & $3(3.2)$ & $93(15.9)$ \\
\hline Post-colonial & $121(97.6)$ & - & $1(0.8)$ & $1(0.8)$ & $1(0.8)$ & $124(21.2)$ \\
\hline Administrative & $156(96.3)$ & - & $1(0.6)$ & $1(0.6)$ & $4(2.5)$ & $162(27.7)$ \\
\hline Traditional & $109(99.1)$ & - & $1(0.9)$ & - & - & $110(18.8)$ \\
\hline The Fringe & $90(93.8)$ & - & - & $1(1.0)$ & $5(5.2)$ & $96(16.4)$ \\
\hline Total & $565(96.6)$ & 1(.17) & $3(0.51)$ & $3(0.51)$ & $13(2.2)$ & 585 \\
\hline & ommercial-us & ntensity & Iration of the $r$ & tropolis & & \\
\hline $\begin{array}{l}\text { High } \\
\text { Commercial- } \\
\text { use }\end{array}$ & $366(96.1)$ & $1(0.3)$ & $2.05(0.5)$ & $2(0.5)$ & $8(2.1)$ & $379(64.8)$ \\
\hline $\begin{array}{l}\text { Low } \\
\text { commercial use }\end{array}$ & 199 (96.6) & - & $1(0.5)$ & $1(0.5)$ & $5(2.5)$ & $206(35.2)$ \\
\hline Total & $565(96.6)$ & 1(.17) & $3(0.51)$ & $3(0.51)$ & $13(2.2)$ & 585 \\
\hline
\end{tabular}

Comparatively, observed differences in the pattern of use-intentions of buildings at completion time between the High-and Low-commercial regional classification scheme appear less distinguishing. For example, the $96.1 \%$ devoted to residential use in the High commercial area comes somewhat close to the $96.6 \%$ in the Lowcommercial region. In both regions also, $0.5 \%$ of their buildings were respectively designated for commercial purpose.

The current pattern of actual building usage however differs in varying degrees from the original use-intentions, an indication that use-conversions have occurred, with no record to ascertain the legal validity or otherwise of such useconversions. The next section examines the pattern of inter-use conversion which occurred between the earmarked uses of buildings and their current uses, disregarding the legal validity of such conversions.

\section{Inter-Use Conversion Pattern by Metropolitan Regions}

Tables $2 \mathrm{a}$ and $2 \mathrm{~b}$ illustrate the inter-use patterns of building conversion across the metropolitan regions of Lagos. The first table illustrates the use-conversion pattern for the five-fold regional conception of the metropolis, while the second table illustrates the same information for the commercial-use schematic configuration of the metropolis. As illustrated in Table 1, most of the buildings across the metropolitan regions were conceived and constructed for residential-use and later got partly or completely converted to other uses.

In Ikeja area, residential usage retains only $16 \%$ of its original stock and receives no cross-transfer from other uses. It lost 
$10.3 \%$ of its aggregate stock to 'commercial use', and experienced the maximum loss $(71.2 \%)$ to the mixed use. Use-conversion pattern in Mainland is somewhat similar to that of Ikeja, except that $6.7 \%$ of its current stock was a gain from the 'mixed-use' category. In all, while Mainland retains 15.7 per cent of its original stock, it lost $13.5 \%$ to commercial use and $69.7 \%$ to the mixed-use category. The observed use-conversion pattern which characterized Ikeja and Mainland seems to characterize the remaining three districts. Indeed, the maximum loss by the residential use is observed in Somolu, which lost $85.2 \%$ of its residencedesignated buildings to mixed use.

Table 2a: Inter-use conversion of buildings in Lagos metropolis' historico-administrative regions

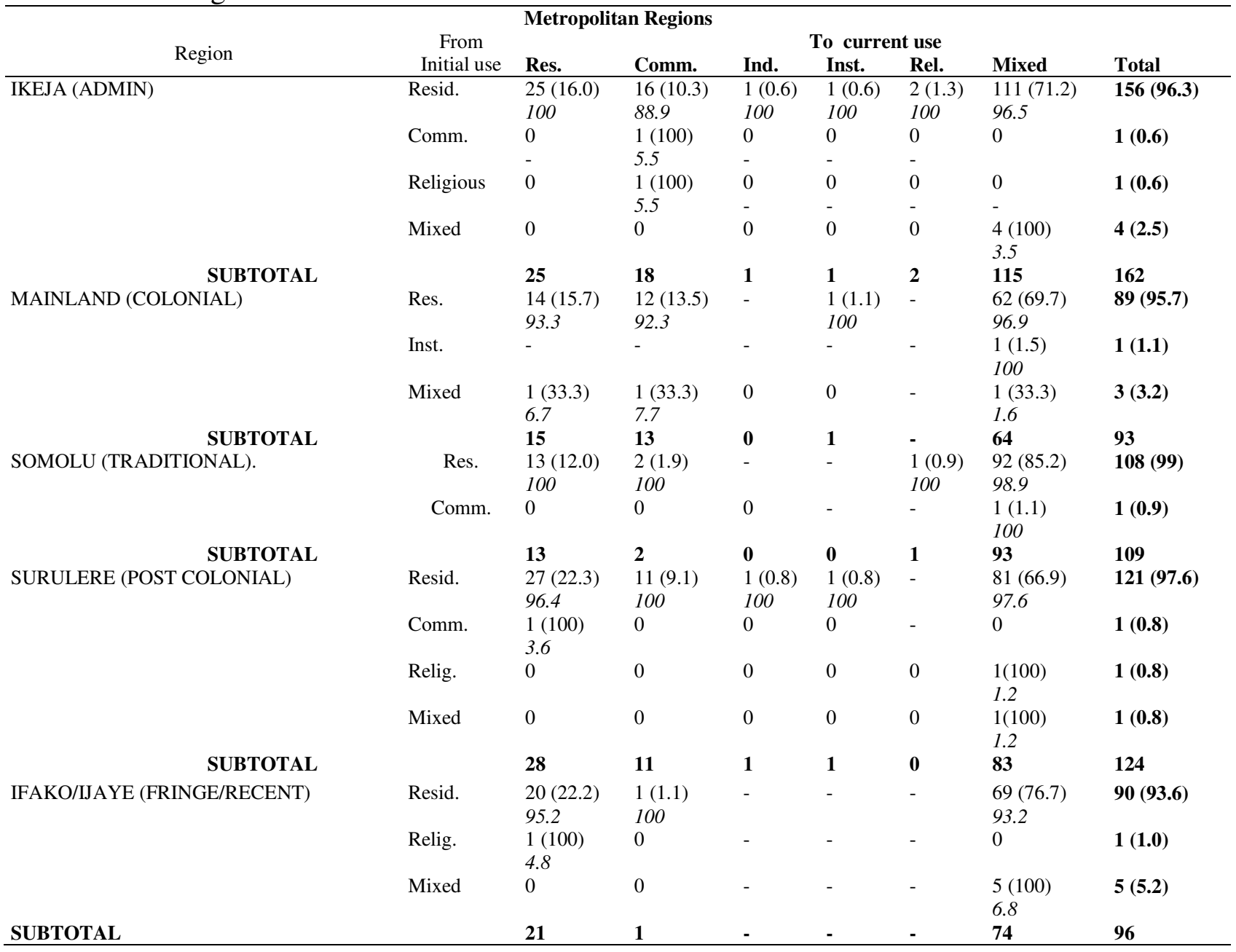

Table $2 \mathrm{~b}$ below shows the crisscross pattern of gain and loss under the commercial-use categorization scheme. The residence-designated buildings in the 'high-commercial' area retains 18 percent and lost $82 \%$ to other uses; with the modal loss $(69.7 \%)$ to mixed use, from which it gains only $1.5 \%$ of its present stock. 
Generally, only minimal degrees of losses are recorded between other pairs of uses where they occurred at all. For example, in the High-commercial region of the metropolis, the losses by the institutional use to the religion and mixed uses, represent just $4.2 \%$ and 0.4 percent respectively of the current building stocks held by the recipient uses. Also, the losses suffered by the mixed-use in the High commercial region of the metropolis amounts to $25 \%$ of its aggregate building stock. The losses translate to $1.5 \%$ of the total current stock of the residential use compared to $2.4 \%$ for the commercial-use.

Use-transfer of buildings in the lowcommercial region of the metropolis is relatively fewer, although residential-use buildings still suffered the most. For example it lost $81.4 \%$ of its cumulative stock to mixed use, $1.5 \%$ to commercial use and $0.5 \%$ to religious use. Other losses that occur involve losses by the 'commercial' and the 'Religious' uses to the 'mixed' uses. The gain from both sources amounted to $3.5 \%$ of the currently held building stock by the mixed use.

Table 2b: Use conversion of buildings in Lagos' commercially-delineated metropolitan regions

\begin{tabular}{|c|c|c|c|c|c|c|c|c|}
\hline \multicolumn{9}{|c|}{ Commercial-use Intensity metropolitan regions } \\
\hline & \multirow{2}{*}{$\begin{array}{c}\text { From } \\
\text { Initial use }\end{array}$} & \multicolumn{2}{|c|}{ To current use } & \multirow[b]{2}{*}{ Indus } & \multirow[b]{2}{*}{ Inst. } & \multirow[b]{2}{*}{ Rel. } & \multirow[b]{2}{*}{ Mixed } & \multirow[t]{2}{*}{ Total } \\
\hline & & Res. & Commerce & & & & & \\
\hline \multirow[t]{10}{*}{ High Commercial } & \multirow[t]{2}{*}{ Res. } & $66(18.0)$ & $38(10.4)$ & $2(0.5)$ & $3(0.8)$ & $23(6.3)$ & $255(69.7)$ & \multirow[t]{2}{*}{366 (96.6) } \\
\hline & & 97.1 & 92.7 & 100 & 100 & 95.8 & 97.0 & \\
\hline & \multirow[t]{2}{*}{ Comm. } & $1(50)$ & $1(50)$ & 0 & 0 & 0 & 0 & \multirow[t]{2}{*}{$2(0.5)$} \\
\hline & & 1.5 & 2.4 & 0 & 0 & 0 & 0 & \\
\hline & \multirow[t]{2}{*}{ Inst. } & 0 & 0 & 0 & 0 & $1(50)$ & $1(50)$ & \multirow[t]{2}{*}{$2(0.3)$} \\
\hline & & 0 & 0 & 0 & 0 & 4.2 & 0.4 & \\
\hline & \multirow[t]{2}{*}{ Relig. } & 0 & $1(50)$ & 0 & 0 & 0 & $1(50)$ & \multirow[t]{2}{*}{$2(0.5)$} \\
\hline & & 0 & 2.4 & 0 & 0 & 0 & 0.4 & \\
\hline & \multirow[t]{2}{*}{ Mixed } & $1(12.5)$ & $1(12.5)$ & 0 & 0 & 0 & $6(75.0)$ & \multirow[t]{2}{*}{$8(2.1)$} \\
\hline & & 1.5 & 2.4 & 0 & 0 & 0 & 2.3 & \\
\hline SUBTOT & $\mathrm{AL}$ & 68 & 41 & 2 & 3 & 24 & 263 & 379 \\
\hline \multirow[t]{8}{*}{ Low Commercial } & \multirow[t]{2}{*}{ Res. } & 33 (16.6) & $3(1.5)$ & - & - & $1(0.5)$ & $162(81.4)$ & \multirow[t]{2}{*}{$199(94.8)$} \\
\hline & & 100 & 100 & & & 100 & 93.6 & \\
\hline & \multirow[t]{2}{*}{ Comm. } & 0 & 0 & - & - & 0 & $1(100)$ & \multirow[t]{2}{*}{$1(0.5)$} \\
\hline & & & & & & 0 & 0.6 & \\
\hline & \multirow[t]{2}{*}{ Relig. } & 0 & 0 & - & - & 0 & $5(100)$ & \multirow[t]{2}{*}{$5(2.4)$} \\
\hline & & 0 & 0 & & & 0 & 2.9 & \\
\hline & \multirow[t]{2}{*}{ Mixed } & 0 & 0 & - & - & 0 & $5(100)$ & \multirow[t]{2}{*}{$5(2.4)$} \\
\hline & & 0 & 0 & & & 0 & 2.9 & \\
\hline \multicolumn{2}{|c|}{ SUBTOTAL } & 33 & 3 & - & - & 1 & 173 & 210 \\
\hline
\end{tabular}

So far, the patterns of losses and gains respectively among building-use categories and urban regions have been examined. In the next section the two logit models of building-use conversion are compared.
Comparative Logit analysis of UseConversion of Lagos metropolis

Table 3 summarizes the result of the two logit models of use-conversion of building in Lagos using the two different spatial conceptions of the metropolis. A comparison of the 2 models shows that 
Model 1, which depicts the metropolis as five-fold regions, offers a better template for rationally explaining the differences in the incidence of use-conversion of buildings in the metropolis than Model 2, which depicts the metropolis as 'low' and 'high' commercial regions. Specifically the variable 'area', which captures the metropolis as five-fold regions is significant $(\mathrm{p}=.016)$ in Model 1 , while it turns out as insignificant in Model 2 that compartmentalizes the metropolis into two regions. Categorical analysis of the variable 'area' in Model 1 shows that apart from the Mainland region, Ikeja, which is the administrative capital of the state registers the greatest likelihood for building-use conversion. The other three regions; Somolu (traditional); Surulere (Post-Colonial) and Ifako/Ijaye (the fringe), all had lesser likelihood for useconversion as shown by their negative $\beta$ co-efficient values, in contrast to that of Ikeja which is the reference category.

In both models, six of the nine hypothesized variables exhibit significance explanations. While the variable 'area' was significant in Model 1 and not in Model 2, the variable 'approval status' of the building before completion was significant in Model 2 but not in Model 1. Comparing the other results of the 2 models underscores the fact that the fivefold regionalization of the metropolis in Model 1presents a spatial arrangement in which the factors which propel useconversion decisions exercise differentiated magnitudes of importance among its sub-regions. This attributes is lacking in Model 2. Model 1 in essence offers a better regionalization approach than Model 2 for understanding and tackling the activity or decision of useconversion of buildings in the metropolis. To be specific, both the Cox \& Snell's $\mathrm{R}^{2}$ $(32.1 \%)$ and Negelkerke's $\mathrm{R}^{2}(44.7 \%)$ are reasonably higher in Model 1 than their corresponding values in Model 2 being respectively $29.2 \%$ and $40.6 \%$. Likewise, the accuracy of their correctly classifying use-converted and unconverted buildings is higher for Model 1 (83.8\%) than for Model 2 , which is $79.5 \%$. The inference from this is that the degree of success achievable in the implementation of physical development regulation and controls in a metropolis depends on the ability to identify and employ the most appropriate spatial configuration that would best serve that purpose. 
Table 3: Comparative use-conversion logistic model of two depictions of Lagos metropolis

\begin{tabular}{|c|c|c|c|c|c|c|c|c|}
\hline \multirow{2}{*}{$\begin{array}{l}\text { Variables in } \\
\text { the Equation }\end{array}$} & \multicolumn{4}{|c|}{ MODEL 1} & \multicolumn{4}{|c|}{ MODEL 2} \\
\hline & $\mathrm{B}$ & Wald & Sig. & $\operatorname{Exp}(B)$ & $\mathrm{B}$ & Wald & Sig. & $\operatorname{Exp}(B)$ \\
\hline AREA & & 12.133 & $.016^{*}$ & & - & - & - & - \\
\hline AREA(1) & .551 & 1.729 & .189 & 1.735 & .253 & 1.066 & .302 & 1.288 \\
\hline $\operatorname{AREA}(2)$ & -.176 & .306 & .580 & .839 & - & - & - & - \\
\hline $\operatorname{AREA}(3)$ & -.086 & .055 & .814 & .917 & - & - & - & - \\
\hline $\operatorname{AREA}(4)$ & -.925 & 6.595 & .010 & .397 & - & - & - & - \\
\hline AGE & - & 6.091 & $.048 *$ & - & - & 8.736 & $.013^{*}$ & - \\
\hline $\operatorname{AGE}(1)$ & -2.669 & 5.329 & .021 & .069 & -3.014 & 7.127 & .008 & .049 \\
\hline $\operatorname{AGE}(2)$ & -2.307 & 3.751 & .053 & .100 & -2.519 & 4.668 & .031 & .081 \\
\hline APPROVAL & - & .518 & .772 & - & - & 6.192 & $.045^{*}$ & - \\
\hline APPROVAL(1) & -.395 & .512 & .474 & .674 & -.758 & 2.020 & .155 & .468 \\
\hline APPROVAL(2) & -.308 & .264 & .608 & .735 & -.057 & .010 & .922 & .944 \\
\hline MAINUSE & - & .280 & .991 & - & - & .090 & .999 & - \\
\hline MAINUSE(1) & .209 & .094 & .759 & 1.232 & .178 & .065 & .799 & 1.195 \\
\hline MAINUSE(2) & .880 & .241 & .624 & 2.410 & .425 & .055 & .815 & 1.530 \\
\hline MAINUSE(3) & -18.793 & .000 & 1.000 & .000 & $\begin{array}{c}- \\
19.453\end{array}$ & .000 & 1.000 & .000 \\
\hline MAINUSE(4) & -.008 & .000 & .996 & .992 & .240 & .024 & .877 & 1.271 \\
\hline FLOOR & - & 7.214 & $.027 *$ & & - & 7.230 & $.027 *$ & - \\
\hline FLOOR(1) & -.074 & .028 & .866 & .928 & -.155 & .128 & .720 & .856 \\
\hline FLOOR(2) & -.713 & 4.993 & .025 & .490 & -.731 & 5.474 & .019 & .481 \\
\hline ROOMS & - & .210 & .900 & - & - & .650 & .723 & - \\
\hline ROOMS(1) & -.333 & .186 & .666 & .716 & -.398 & .289 & .591 & .672 \\
\hline $\operatorname{ROOMS}(2)$ & -.197 & .142 & .706 & .821 & -.401 & .639 & .424 & .670 \\
\hline $\begin{array}{l}\text { RESIDENTIAL } \\
\text { WEIGHT }\end{array}$ & - & 1.656 & .437 & - & - & 1.003 & .606 & - \\
\hline $\begin{array}{l}\text { RESIDENTIAL } \\
\text { WEIGHT(1) }\end{array}$ & -.379 & .287 & .592 & .684 & -.243 & .129 & .719 & .784 \\
\hline $\begin{array}{l}\text { RESIDENTIAL } \\
\text { WEIGHT(2) }\end{array}$ & -.613 & 1.624 & .203 & .542 & -.452 & .974 & .324 & .636 \\
\hline OWNER(1) & 1.882 & 35.674 & $.000^{*}$ & 6.564 & 1.955 & 39.720 & $.000^{*}$ & 7.067 \\
\hline TYPETITLE & - & 106.610 & $.000 *$ & - & - & 113.582 & $.000 *$ & - \\
\hline TYPETITLE(1) & -1.483 & 3.992 & .046 & .227 & -1.472 & 3.946 & .047 & .229 \\
\hline TYPETITLE(2) & 1.540 & 4.412 & .036 & 4.665 & 1.629 & 4.933 & .026 & 5.100 \\
\hline Constant & 2.561 & 2.683 & .101 & 12.954 & 2.842 & 3.511 & .061 & 17.146 \\
\hline & OTHI & SUMMA & $\mathrm{CO}$ & RATI & PAK & TERS & & \\
\hline Cox \& Snell's $\mathbf{R}^{2}$ & & $32.1 \%$ & & & & $29.2 \%$ & & \\
\hline $\begin{array}{l}\text { Nagelkerke's } \mathbf{R}^{2} \\
\text { Accuracy of } \\
\text { correctly } \\
\text { predicting USE- } \\
\text { CONVERSION }\end{array}$ & & $44.7 \%$ & & & & $40.6 \%$ & & \\
\hline
\end{tabular}




\section{Conclusion and Recommendation}

This study justified its research focus by highlighting the preponderant neglect of the import of property-use conversion on housing deficit analysis in many cities of the developing world. It therefore examines property-use conversion in Lagos metropolis in the context of two premises. The first is its direct impact on residential-housing. The second is the review by the government of the Pre-2007 edict, which proscribed unapproved construction and conversion of properties in the metropolis. It justified the review by pointing to the continuous enlargement of the metropolis and its reductionist effect on the monitoring effectiveness of the relevant agency.

This paper has shown that indeed, residential-use remains the major victim of building-use conversion in the metropolis. The scenario threatens the social development goal of improved access to housing by the UNHabitat and governments in cities of the developing nations. Secondly, obtained results of the model has shown that the ability to effectively implement the provision of the property development edict would depend on the ingenuity to devise the appropriate conception of the metropolis which can reveal significant variations in the degrees to which the development and redevelopment of buildings occur in the metropolis. This would assist primarily at uncovering special 'spatial clusters', which require focused attention rather than employing the holistic metropolitan policing strategy which is highly unrealistic.

The present analysis for example shows that the five-fold regionalization conception performs better than a two-fold regionalization which employed the commercial-intensity differentials of the metropolis. There are however other regional-categorization criteria that may have to be explored before any decision may be arrived at with regards to the most appropriate regional configuration for addressing physical development monitoring and control in the metropolis. Such criteria may be derived from the physical, the cultural or the economic characterization of the metropolis. This is the challenge that is set before the research community and the physical development regulatory agencies.

Furthermore, the workability of the other option which introduces financial penalty is suspect, given the antecedent of corruption associated with the bureaucracy of property development regulations in Lagos (Aluko, 2011). Introducing financial penalty in such a setting will most likely compromise the original unadulterated intentions of the propertydevelopment regulations, thereby undermining the realization of other equally-important objectives, particularly that of improved access to residentialhousing in the metropolis.

\section{References}

Ademiluyi, I.A. and Raji, B.A. (2008). Public and Private Developers as Agents in Urban Housing Delivery in Sub Saharan Africa: The Situation in Lagos State. Humanity of Social Sciences Journal, 3(2): 143-150.

Akinmoladun, O.I. and Oluwoye, J.O. (2007). An Assessment of why the problems of Housing shortages Persist in Developing Countries: A Case Study of Lagos metropolis, Nigeria. Pakistan Journal of Social Sciences. 4(4): 589-598 
Alufohai, A.J. (2013). The Lagos State 2010 Mortgage Law and the Supply Of Housing; being A Paper Presented at the International Federation of Surveyors Working week At The

International Conference Center and Nicon Luxury Hotel Abuja, Nigeria, 6-10 May 2013

Aluko, O. (2011). Development Control in Lagos State: an Assessment of Public Compliance to Space Standards for Urban Development. African Research Review International Multidisciplinary Journal, 5(5): Serial No. 22, 169-184

Bolnick, J., Bradlow, B. and Shearing, C. (2011). Housing, institutions, money: the failures and promise of human settlements policy and practice in South Africa. Environment \& Urbanisation, 23(1): 267-275, April 2011.http://www.sdinet.org/media/up load/documents/EU2011231Bradlow etal.pdf

Djibril, K., Yun, Q., Ousmane, D. and Xiangrong, W. (2012). Processes and challenges of urban development in Côte d'Ivoire (Africa) with case study of Abidjan City. Journal of Geography and Regional Planning, 5(13): 353-361.

Enisan, O. and Ogundiran, A. (2013). Challenges of Housing Delivery in Metropolitan Lagos, Research on Humanities and Social Sciences 3(20): 1-8.

Franklin, S. (2011). Enabled to Work? The Impact of Housing Subsidies on Slum Dwellers in South Africa November 29, 2011.Avaliable at: https://editorialexpress.com/cgibin/co nference/download.cgi?db_name=CS AE2012\&paper_id=316
Housing Development Agency (HDA) (2012) South Africa: Informal settlements status.Research report, HDA, South Africa. Available at: http://www.upgradingsupport.org/upl oads/files/South_Africa.pdf

Hardoy, J. and Satterthwaite, D. (1989). Shelter: need and response, John Wiley, Chichester.

Lagos State of Nigeria Official Gazette (2007). January, No. 6, vol. 40 Section 60(1)

Mabogunje, A.L. (1980). The development process: A spatial perspective. London, Hutchinson Mabogunje A. L. (2007) Developing Mega Cities in Developing Countries, being a lecture delivered at a Colloquim organized by the Department of Geography, University of Lagos on Wednesday, 12 September, 2007

Magigi, W. and Majani, B.B.K. (2006) Housing Themselves in Informal Settlements: A Challenge to Community Growth Processes, Land Vulnerability and Poverty Reduction in Tanzania; being a paper presented at the Conference on Promoting Land Administration and Good Governance 5th FIG Regional Conference Accra, Ghana, March 811, 2006

Mistro, R.D. and Hensher, A.D. (2009). Upgrading informal settlements in South Africa: policy, rhetoric, and what residents really value. Housing Studies, 24 (3):333-354.

Nubi, O.T. (2008), Affordable Housing Delivery in Nigeria. The South African Foundation International Conference and Exhibition, Cape Town, October, Pp. 1-18.

Opoko, A.P. and Oluwatayo, A. (2014). Trends in Urbanisation: Implication 
for Planning and Low-Income Housing Delivery in Lagos, Nigeria Architecture Research, 4(1A): 15-26

Oshodi, L. (2010). Housing, Population and Development in Lagos, Nigeria. Http://oshlookman.wordpress.com/20 10/11/24/housing-situation-in-LagosNigeria/Accessed 5/8/2016.

Ukwayi, J.K., Eja, E., Ojong, F.E. and Otu, J.E. (2012). An Assessment of Housing Delivery in Nigeria: Federal Mortgage Bank Scenario
SouthAfrica.info (2016). Social Development : Houses for Everyone http://www.southafrica.info/about/so cial/govthousing.htm\#.V7sIHVQrI1I Accessed 22/8/2016

Ziblim, A. (2013). The Dynamics of Informal Settlements Upgrading in South Africa: Legislative and Policy Context, Problems, Tensions, and Contradictions: A Study Commissioned by Habitat for Humanity International/EMEA Office Bratislava, Slovakia 